\title{
CONTROLE PARLAMENTAR POR MEIO DOS DISCURSOS DOS DEPUTADOS NA 55ª LEGISLATURA
}

\section{PARLIAMENTARY CONTROL THROUGH THE SPEECHES OF DEPUTIES IN THE 55TH LEGISLATURE}

\author{
Ronaldo Quintanilha da Silva *
}

\begin{abstract}
Resumo
Examinou-se o uso dos instrumentos formais de fiscalização parlamentar postos à disposição do parlamentar de 1988 a 2018 e dos discursos dos deputados federais com viés fiscalizatório de 2 de fevereiro de 2015 a 31 de janeiro de 2019 (55 Legislatura). O objetivo é quantificar os Instrumentos de Fiscalização e Controle (control tools) e a relação com os discursos proferidos durante o Grande Expediente na Câmara dos Deputados. A metodologia é baseada em técnica quantitativa, especialmente na comparação de variáveis totalizantes, e qualitativa, a fim de classificar proposições e interpretar os resultados. Conclui-se que o controle parlamentar em termos numéricos decresceu, assim como a participação dos discursos contendo expressões ligadas à fiscalização. Com efeito, há possibilidade de migração dos deputados para outras plataformas e/ou diminuição da relevância de se fiscalizar por meio dos discursos. Dessa forma, ressalta-se a importância do estudo da função típica de fiscalizar do Poder Legislativo, com intuito de entender seu funcionamento e apontar eventuais aperfeiçoamentos.
\end{abstract}

Palavra-chave: Poder Legislativo; Fiscalização Parlamentar; Instrumentos de Fiscalização e Controle; Discursos.

\begin{abstract}
This article examines the use of formal parliamentary oversight instruments made available to parliamentarian from 1988 to 2018 and the speeches of federal deputies with a supervisory bias from February 2, 2015 to January 31, 2019 (55th Legislature). The objective is to quantify the control tools in relation to the speeches made during the Great Expedition in the Chamber of Deputies. The methodology is based on quantitative technique, especially in the comparison of totalizing variables, and qualitative, with the objective of classifying propositions and interpreting the results. It is concluded that parliamentary control in numerical terms decreased, as well as the participation of the speeches containing expressions related to the inspection. In effect, the possibility of migrating deputies to other platforms and/or reducing the transformation of inspecting themselves through speeches. Thus, the importance of studying the typical supervisory function of the Legislative Power is emphasized, in order to understand its operation and improvements.
\end{abstract}

Keywords: Legislative Power; Parliamentary Oversight; Oversight and Control Tools; Speeches.

\footnotetext{
* Mestre em Poder Legislativo pelo Centro de Formação da Câmara dos Deputados (CEFOR/CD)/Brasil. E-mail: professor.ronaldoquintanilha@gmail.com.
} 


\title{
Introdução ${ }^{1}$
}

O poder Legislativo exerce as funções típicas de legislar e fiscalizar. A função de controle e a sua materialização ocorrem por meio de Instrumentos de Fiscalização e Controle - IFC (control tools) utilizados pelos integrantes do Congresso Nacional (CN), que pode ser medida e comparada com as iniciativas legislativas de projetos de lei e outros. Desse modo, apresenta-se a representação da função de fiscalização frente à legislativa desde 1988 até 2018 e, principalmente, em que medida são utilizadas as expressões vinculadas ao controle nos pronunciamentos dos deputados ao utilizar o tempo de Grande Expediente ${ }^{2}$ na Câmara dos Deputados (CD) no período de 2 de fevereiro de 2015 a 31 de janeiro de 2019 (55 Legislatura).

A função típica de fiscalização parlamentar é também conhecida como controle externo, cujo titular é o CN, conforme disposição do art. 70 da Constituição Federal de 1988 - CF/88 (BRASIL, 2020a), transcrito a seguir:

\begin{abstract}
Art. 70. A fiscalização contábil, financeira, orçamentária, operacional e patrimonial da União e das entidades da administração direta e indireta, quanto à legalidade, legitimidade, economicidade, aplicação das subvenções e renúncia de receitas, será exercida pelo Congresso Nacional, mediante controle externo, e pelo sistema de controle interno de cada Poder (BRASIL, 2020a).
\end{abstract}

A Constituição, ao listar as competências exclusivas e indelegáveis do Congresso Nacional, em seu art. 49, inciso X, estabelece a missão de "fiscalizar e controlar, diretamente, ou por qualquer de suas Casas, os atos do Poder Executivo, incluídos os da administração indireta" (BRASIL, 2020a).

Nesse contexto, busca-se investigar o funcionamento da função de fiscalização parlamentar, o objetivo consiste, principalmente, em representar de forma numérica o volume do controle parlamentar vocalizado nos discursos parlamentares do Grande

\footnotetext{
${ }^{1}$ Agradeço as valiosas contribuições dos pareceristas, especialmente quanto à estruturação do artigo.

${ }^{2} \mathrm{O}$ Grande Expediente representa o período da sessão plenária, a iniciar-se às dez ou às quinze horas, conforme o caso, com duração improrrogável de cinquenta minutos, distribuída entre os oradores inscritos. Encerrado o Pequeno Expediente, será concedida a palavra aos deputados inscritos para o Grande Expediente, pelo prazo de vinte e cinco minutos para cada orador, incluídos nesse tempo os apartes (Art. 66 e 87 do RICD) (BRASIL, 2020c).
} 
Expediente. A pesquisa se baseou ainda em dados e procedimentos aplicados ao estudo bem mais abrangente envolvendo outras hipóteses. ${ }^{3}$

A comunicação é um mecanismo indispensável da política, figurando como instrumento central nas relações de poder, envolvendo os representantes eleitos e a sociedade (FOUCAULT, 2012). A atividade de controle pode ser verificada não apenas pelo uso das proposições com o propósito de questionar ou vigiar as ações do Executivo, mas pelo emprego do valioso tempo disponível para uso da palavra. Uma das principais ações do deputado consiste em divulgar o andamento de seu mandato, por meio de pronunciamentos. O tempo é disputado entre os 513 integrantes da Câmara dos Deputados, por isso o seu Regimento Interno (RICD) estabelece regras rígidas para o usufruto de minutos ao microfone. De fato, "parlamento" tem origem em parlar, verbo italiano, que significa "falar". A Câmara é uma caixa de ressonância, na qual deve ecoar a voz daqueles ali representados. Assim, além das proposições, verifica-se se esse tempo tem sido utilizado com alguma referência ao controle e fiscalização.

Em estudo aprofundado sobre as transmissões das sessões plenárias em países do continente americano, identificaram-se vários tipos de mediações concorrentes entre os parlamentos e os cidadãos. Dessa forma, os meios de comunicação representam parte dessa tarefa. Ou seja, o uso da Tribuna pelos deputados com a transmissão por vários canais de comunicação, confirma o Legislativo como elemento de mediação própria ao abrir janelas comunicativas, entre elas, a das transmissões ao vivo para que o cidadão observe a sessão plenária com os próprios olhos (CARVALHO, 2020).

$\mathrm{O}$ ato de escolha do tema pelos oradores caracteriza os objetivos de seu mandato, como apresentam Luis Felipe Miguel e Fernanda Feitosa:

Cabe a cada deputada ou deputado definir qual é seu alvo (ou quais são os
alvos) ao discursar. As temáticas que elegem indicam também as prioridades
de seu mandato. Tais prioridades, porém, não nascem apenas de suas
convicções ou inclinações; são determinadas de forma estratégica, tendo em
vista as oportunidades abertas no campo e as chances de êxito na carreira
política (MIGUEL; FEITOSA, 2009, p. 206-207).

${ }^{3} \mathrm{Na}$ minha dissertação de mestrado, foram listadas seis hipóteses de pesquisa (SILVA, 2020). 
Nessa linha, Davi Cordeiro Moreira menciona os meios institucionais colocados à disposição dos parlamentares tanto na Câmara dos Deputados (CD) quanto no Senado Federal (SF):

\begin{abstract}
Os regimentos internos das duas casas legislativas garantem a palavra como poder e direito do exercício parlamentar brasileiro. Os congressistas têm acesso a diversos meios de comunicação com recursos humanos e materiais financiados pela $\mathrm{CD}$ e pelo $\mathrm{SF}$ : tv, rádio, internet, jornal e outros meios institucionais (MOREIRA, 2016, p. 40).
\end{abstract}

Desse modo, entende-se que há argumentos para se empreender a pesquisa, pois está-se diante de uma função típica do Parlamento que não atrai tanto o esforço de estudiosos, conforme afirma Cintra "o controle do Poder Executivo pelo Poder Legislativo é algo pouco estudado no mundo e, ainda menos, no Brasil" (CINTRA et al., 2015, p. 115). Ao mesmo tempo, não há precedente de investigações tratando do uso do discurso parlamentar como mais um mecanismo de controle parlamentar.

Em Brasília, o projeto arquitetônico do Palácio do Congresso Nacional está erguido em terreno elevado, acima dos demais palácios, sendo uma forte expressão artística do status de vigilante. Ademais, é exatamente nesse local que o Chefe do Poder Executivo brasileiro, escolhido pelos cidadãos e diplomado pela Justiça Eleitoral, faz seu compromisso de posse, perante os representantes do povo (art. 57, § $3^{\circ}$, da $\mathrm{CF} / 88$ ) (BRASIL, [2020a]).

O Congresso se reúne em sessão conjunta e solene para que o eleito faça seu juramento, que de tão importante está estabelecido na própria Carta Magna: a autoridade deve "manter, defender e cumprir a Constituição, observar as leis, promover o bem geral do povo brasileiro, sustentar a união, a integridade e a independência do Brasil" (art. 78 da CF/88) (BRASIL, 2020a).

O artigo está dividido nesta introdução, depois, na exposição dos procedimentos de pesquisa e coleta de dados; em seguida, apresentação do emprego dos instrumentos de controle em comparação com as iniciativas legislativas, as quais permitiram demonstrar a medida do volume da fiscalização parlamentar. Depois, o tema centra: a correspondência com o uso do discurso. No final, a conclusão. 


\section{Procedimentos de pesquisa e coleta de dados}

Em relação à metodologia, baseou-se em análises quantitativas e qualitativas, a partir da base de dados, contendo os instrumentos de fiscalização. Também se adaptou o modelo utilizado por Lemos (2005), para mensurar o volume de atividade de controle, e por Raposo (2015), no tocante aos discursos. Como dito, a parte mais geral possui proposições retiradas do Sistema de Informações Legislativas (Sileg) ${ }^{4}$ da CD e do sistema disponível na página institucional do SF (BRASIL, 2020e). Quanto aos discursos, retiraram-se dados da base de discursos da CD (BRASIL, 2020b).

Primeiramente, definiu-se o período de Grande Expediente em Plenário, por se tratar de um período em que o parlamentar pode discursar por mais tempo e para o qual se deve inscrever com antecedência. Nesse espaço, ele pode tratar de forma mais demorada sobre assuntos de sua escolha. Assim, utilizar esse momento para abordar fiscalização é um indicativo da relevância dessa atividade.

Quanto ao escopo, divide-se em uma parte geral, envolvendo as duas Casas Legislativas (Câmara e Senado) e contabilizando dados desde 1988; uma parte específica, aprofundando os estudos na Câmara dos Deputados, incluindo dados dos discursos desde 2001. No tocante aos instrumentos utilizados para pesquisa, as proposições selecionadas atenderam ao critério de agrupar o maior número possível de tipologias, descartando as oriundas de comissões mistas (posicionadas na estrutura do $\mathrm{CN}$ ), e as produzidas no âmbito das Comissões Parlamentares de Inquérito (CPI), que já detém a atenção dos cientistas políticos. Desse modo, o propósito é consolidar dados acerca de seis tipos de proposições, as quais foram incluídas na pesquisa que deu base para este artigo: a) requerimentos de audiência pública (REQ); b) requerimentos de convocação de autoridade (RCA); c) requerimentos de informação (RIC); d) propostas de fiscalização e controle (PFC); e) projetos de decreto legislativo (PDC); e f) solicitações de informação ao Tribunal de Contas da União (SIT).

\footnotetext{
${ }^{4}$ É o principal sistema de registro da informação legislativa da Câmara dos Deputados, tendo como foco o processo de tramitação de proposições (BRASIL, 2020d).
} 
Os instrumentos envolvem SITs, PFCs, PDCs (fundamento no inciso V do art. 49 da CF/88) (BRASIL, 2020a), RCAs e RICs, incluindo os que foram apresentados nas comissões e no plenário. Os REQs não podem ser inseridos em sua totalidade, pois nem todos têm a finalidade de "fiscalizar", apesar de ser possível que ocorram várias abordagens e o alcance de objetivos indiretos em uma mesma audiência pública. Porém, para não cometer exageros indevidos na contagem dos instrumentos, decidiu-se excluir os requerimentos das comissões especiais ${ }^{5}$, por estarem voltadas intrinsicamente à análise de um projeto de lei ou proposta de emenda à Constituição. Além disso, foram suprimidos os requerimentos das comissões parlamentares de inquérito e das comissões mistas (Comissão Mista de Planos, Orçamentos Públicos e Fiscalização - CMO etc.). Assim, estão inseridos os requerimentos de audiências apresentados às comissões permanentes e às comissões externas ${ }^{6}$ da $\mathrm{CD}$ e do $\mathrm{SF}$.

Com isso, os requerimentos de audiência totalizaram-se 3.796 na Câmara e 1.607 no Senado, logo, exigiria esforço considerável de análise, o que implicou na adoção de técnica de amostragem, cuja fórmula ${ }^{7}$ está abaixo descrita:

$$
n=\frac{N}{1+N e^{2}} \quad \begin{aligned}
& \text { Onde se lê: } \\
& \mathrm{n}=\text { amostra } \\
& \mathrm{N}=\text { tamanho da população } \\
& \mathrm{e}=\operatorname{erro}(5 \%)
\end{aligned}
$$

Assim, a partir da amostra, analisaram-se os requerimentos de audiência para identificar se havia o objetivo de controlar, vigiar, fiscalizar, avaliar, cobrar as ações do Poder Executivo. É preciso destacar que as reuniões podem não ter seguido estritamente o definido no texto da proposição. Da mesma forma, não obstante o conteúdo do requerimento não indicar procedimentos de conferência, durante a reunião, tal situação pode ter acontecido. Portanto, para ser classificado como de fiscalização a ementa do requerimento, que consubstancia o objeto da lei, deve conter as finalidades de fiscalizar,

\footnotetext{
${ }^{5}$ Segundo art. 34 do RICD, as comissões especiais serão constituídas para dar parecer sobre proposta de emenda à Constituição e proposições que versarem matéria da competência de mais de três comissões (BRASIL, 2020c). No SF, o regimento não prevê expressamente o tipo "especial". As comissões temporárias podem ser internas (atribuição específica) e externas (para congressos, solenidades e outros atos públicos), conforme arts. 71 e 74 do RISF (BRASIL, 2018).

${ }^{6}$ Comissão permanente é perene na estrutura da respectiva Casa. Comissão externa possui um tempo de funcionamento, não é perene (arts. 32 e 38, RICD e art. 72, RISF) (BRASIL, 2020c; 2018).

${ }^{7}$ Fórmula de Yamani, conforme Marciano (2016).
} 
exigir prestação de contas ou explicar motivos para determinada decisão ou gasto público etc.

Nesse sentido, considerou-se a amostra dos requerimentos de audiência na CD de 362 e no SF de 320, e depois de aplicar a eles o procedimento de classificação separando em potencial fiscalizatório e não fiscalizatório, obteve-se o coeficiente de fiscalização de requerimento de audiência pública (REQ_c), no valor de 0,3205 para CD e de 0,2875 para o SF, perceba a proximidade entre ambos, conforme a tabela:

Tabela 1 - Amostra dos requerimentos de audiência públicas apresentados na CD e no SF no período de 2015 a $2018^{*}$

\begin{tabular}{lccrc}
\hline TIPO & REQ CD & \% & REQ SF & \% \\
\hline Não Fiscalizatório & 246 & $67,95 \%$ & 228 & $71,25 \%$ \\
Fiscalizatório & 116 & $32,05 \%$ & 92 & $28,75 \%$ \\
\hline Total & 362 & $100 \%$ & 320 & $100 \%$ \\
\hline
\end{tabular}

Fonte: Elaboração própria, a partir de dados do Sileg e site do SF.

* Requerimentos de audiência pública apresentados nas comissões permanentes e externas na CD (3.796) e no SF (1.607), cujas amostras são, respectivamente, 362 e 320 .

O modelo adotado teve por base a pesquisa de Lemos (2005), que quantifica a atividade de controle em uma série histórica de 1988 a 2004. Cabe marcar as diferenças das variáveis utilizadas, o estudo de Lemos demonstra que há atividade de controle por meio de instrumentos formais, e que ela tem aumentado significativamente desde 1988, em relação ao somatório das propostas apresentadas no Congresso. Destaca-se que esse cômputo de propostas apresentadas inclui tão-somente as apresentadas no Plenário: propostas de controle compreendem convocações de ministros (excluídas as de comissões), propostas de fiscalização e controle e requerimentos de informação. Exclui, portanto, toda a atividade comissional de controle, como audiências públicas, comissões parlamentares de inquérito, convocações e "convites" a autoridades para se apresentarem nas comissões. 
Com relação às proposições legislativas, Lemos (2005) inseriu as propostas de emenda constitucional (PEC), projetos de lei ordinária (PL) e lei complementar (PLC). Excetuam-se requerimentos de caráter administrativo ou processual. Segundo ela, trata-se do total de propostas, uma vez que todas devem ser apresentadas e lidas em plenário antes de seguirem às comissões.

Nota-se, contudo, que seria interessante acrescentar outras proposições de caráter legislativo e os seis tipos selecionados de Instrumentos de Fiscalização e Controle. Ao se separar apenas os três tipos de propostas legislativas mencionadas, quais sejam: PEC, PL e PLC, acaba-se por subestimar a variável total de proposição legislativa e, por conseguinte, levar ao entendimento de que o controle ocupa maior espaço do que realmente preenche. A consolidação das proposições acerca da produção legislativa inicialmente seguiu o modelo adotado por Lemos (2005), mas identificou-se a possibilidade de empregar novo método mais amplo e realista para comparar a relevância da fiscalização parlamentar. Desse modo, a variável de atividade legislativa reúne: projetos de lei ordinária e complementar, projetos de resolução, projetos de decreto legislativo (exceto os que se referem ao inciso V do art. 49 da CF/88) (BRASIL, 2020a), medidas provisórias, proposta de emenda à Constituição, requerimentos de audiência pública sem viés fiscalizatório e requerimentos do processo legislativo. E do lado do controle estão todos os RICs, PFCs, PDCs (inciso V do art. 49 da CF/88) (BRASIL, 2020a), SITs e RCAs e os REQs de conteúdo fiscalizatório.

No âmbito dos discursos, utilizou-se o estudo de Raposo (2015), que abrange o período de 1995 a 2014, cinco legislaturas, e revelou como a questão do controle parlamentar não atraiu a atenção dos deputados. Em vinte anos, os parlamentares que se revezaram no Plenário Ulisses Guimarães da CD para discursar, e o resultado, segundo o autor, é o seguinte:

\footnotetext{
De um total de 16.502 vezes em que o vocábulo "fiscalização" foi pronunciado por um parlamentar no Plenário, apenas cerca de $12 \%$ referem-se, de algum modo, à atividade de fiscalização e controle. No entanto, a maior parcela desses mesmos discursos $(7 \%)$ refere-se à CFFC, muito mais como comentários acerca de suas atividades ou eventos por ela promovidos (RAPOSO, 2015, p. 17).
}

Nesse caso, ele utilizou a expressão "fiscalização", e o período iniciou-se em 1995. O autor ainda adentrou em cada discurso para separar aqueles com menção e os de propósitos mais fiscalizatórios. Para adaptação, optou-se em começar pelo ano de 2001, pois foi a partir dessa data que se encontraram os dados sobre os discursos de Grande Expediente disponíveis 
no Banco de Discursos no site da Câmara dos Deputados (BRASIL, 2020b). Vale destacar que não foi objeto de estudo o teor dos discursos, a contagem considerou apenas a menção às palavras estabelecidas. O sistema de busca permite a procura por expressões dentro de cada um dos pronunciamentos transcritos, os quais geraram os registros contabilizados na variável "Disc_c" (Somatórios dos discursos com as expressões de controle).

Desse modo, produziu-se um levantamento sobre os pronunciamentos no Grande Expediente para verificar se o uso dos instrumentos é acompanhado por discursos na mesma linha, com emprego de palavras do campo temático da fiscalização: "TCU”, "CGU”, “Controlar", "Controle", "Fiscalizar" e "Fiscalização".

Então, de 2001 a 2018, foram realizados 38.588 pronunciamentos por centenas de parlamentares. Na sequência, compararam-se os discursos com o uso dos control tools, que também seguiram esse padrão. Depois, as variáveis quantitativas dos discursos foram representadas em porcentagens, ou seja, o quanto representa os discursos com expressões de controle contrapostos ao total de discursos realizados. Por fim, confrontaram-se os dados com a Tabela 2, na qual estão os quantitativos dos IFCs, para verificar se havia correlação. A principal vinculação seria uma correspondência direta entre as tentativas de controle e os discursos de controle ocorrerem no mesmo ano.

Na seção seguinte, será feito o confronto dos instrumento de controle parlamentar e das iniciativas de proposições, neste caso, envolvendo a CD e SF.

\section{Controle parlamentar versus iniciativa de proposições no Congresso Nacional}

De início, destaca-se um discurso de Grande Expediente, em 2 setembro de 2015, quando o deputado Jorge Tadeu Mudalen Cury (PSDB-SP) questiona o desempenho da Agência Nacional de Telecomunicação (Anatel) e a administração de fundos públicos:

\footnotetext{
Um quadro alarmante sobre o funcionamento do setor de fiscalização da ANATEL. Segundo o Conselheiro, a ANATEL finge que multa, e as empresas fingem que pagam as multas. Isso fica claro, Sr. Presidente, nos dados do TCU, que apontam que, do total de multas aplicadas pela ANATEL, apenas 2\% são efetivamente pagas pelas empresas, o que evidencia a situação de baixa eficácia do processo fiscalizatório da agência reguladora do setor de telecomunicações (MUDALEN, 2015).
} 
Durante o discurso, o deputado Sandro Alex (PSD-SP) faz um aparte ${ }^{8}$ e ressalta:

E o Governo o que faz? Tenta encaminhar a esta Casa majoração em fundos que somam bilhões e bilhões de reais e não são aplicados na universalização, na físcalização, como estou a comprovar inclusive com requerimentos de informação que apresentei ao Ministério do Planejamento, ao Ministério da Fazenda e à Secretaria do Tesouro Nacional (MUDALEN, 2015).

No trecho do discurso transcrito, o parlamentar arguiu "E o Governo o que faz?", está-se diante de uma atividade típica do Parlamento: cobrar as ações do Poder Executivo. Assim, recorda-se que o controle parlamentar é a atividade que o Poder Legislativo desenvolve para fiscalizar os atos emanados pelo Executivo. Em seguida, contabilizam-se os instrumentos de controle para mais à frente comparar com os discursos.

O uso de variáveis quantitativas acumulando o total de cada uma das proposições permitiu a comparação da evolução da atividade de controle pelo Parlamento. Nesse caso, foram incluídas proposições desde 2005 até 2018, oriundas da CD e do SF. Pelas seguintes razões: a) atualizar o levantamento feito em Lemos (2005), que analisou o espaço temporal de 1988 até 2004; b) apresentar outra forma de medir a atividade em relação à $55^{\mathrm{a}}$ Legislatura, alterando o computo das proposições legislativas e dos IFC.

A tabela 2, a seguir, contém a série histórica construída por Lemos (2005) de 1998 até 2004 e o período elaborado nesta pesquisa de 2005 até 2018. A coluna "a" possui as proposições legislativas (PEC, PL e PLC); a "b" reúne os RICs, RCAs e PFCs; a "c" é o somatório das duas colunas anteriores; e, por último, a "d" representa em percentual a participação das proposições com objetivo de controle.

Como explicado, ao seguir o mesmo modelo de Lemos (2005), o volume de controle é verificado na coluna “d”. Inicia-se com 7,61\% em 1988 e alcança-se 49,77\% em 1994, ou seja, 700\% de aumento. Em 1992, aconteceu o impeachment do ex-presidente Collor, o presidente Itamar assumiu nos anos de 1993 e 1994, com altas taxas de controle. Na sequência, uma diminuição ocorreu, mas permaneceu acima de $35 \%$ até 2001 . Sob o comando do presidente Fernando Henrique Cardoso, de 1995 a 2002, é possível observar uma tendência de queda da média de controle.

\footnotetext{
8 "Aparte" é a interrupção, breve e oportuna, do orador para indagação, ou esclarecimento, relativos à matéria em debate (art. 176, RICD) (BRASIL, 2020c).
} 
Tabela 2 - Apresentação de proposições legislativas versus fiscalização e controle no período de 1988 a 2018 na CD e no SF

\begin{tabular}{|c|c|c|c|c|}
\hline Ano & $\begin{array}{c}\text { (a) Proposições Legislativas } \\
\text { (PEC e PLs) }\end{array}$ & $\begin{array}{c}\text { (b) Controle } \\
\text { (RIC, RCA, PFC) }\end{array}$ & $\begin{array}{l}\text { (c) Total } \\
(\mathrm{a}+\mathrm{b})\end{array}$ & $\begin{array}{c}\text { (d) } \% \text { do } \\
\text { Total }(\mathrm{b} / \mathrm{c})\end{array}$ \\
\hline 1988 & 1.286 & 106 & 1.392 & 7.61 \\
\hline 1989 & 3.745 & 389 & 4.134 & 9.41 \\
\hline 1990 & 1.902 & 377 & 2.279 & 16.54 \\
\hline 1991 & 3.099 & 1.337 & 4.436 & 30.14 \\
\hline 1992 & 1.318 & 1.073 & 2.391 & 44.88 \\
\hline 1993 & 1.125 & 1.101 & 2.226 & 49.46 \\
\hline 1994 & 646 & 640 & 1.286 & 49.77 \\
\hline 1995 & 2.215 & 1.757 & 3.972 & 44.23 \\
\hline 1996 & 1.824 & 1.152 & 2.976 & 38.71 \\
\hline 1997 & 1.896 & 1.174 & 3.070 & 38.24 \\
\hline 1998 & 1.173 & 1.081 & 2.254 & 47.96 \\
\hline 1999 & 3.383 & 1.879 & 5.262 & 35.71 \\
\hline 2000 & 2.244 & 1.391 & 3.635 & 38.27 \\
\hline 2001 & 2.647 & 1.495 & 4.142 & 36.09 \\
\hline 2002 & 1.964 & 795 & 2.759 & 28.81 \\
\hline 2003 & 3.837 & 1.881 & 5.718 & 32.90 \\
\hline 2004 & 2.551 & 1.516 & 4.067 & 37.28 \\
\hline 2005 & 2.691 & 1.569 & 4.260 & 36,83 \\
\hline 2006 & 2.003 & 864 & 2.867 & 30,14 \\
\hline 2007 & 4.287 & 2.521 & 6.808 & 37,03 \\
\hline 2008 & 2.990 & 1.608 & 4.598 & 34,97 \\
\hline 2009 & 3.476 & 1.222 & 4.698 & 26,01 \\
\hline 2010 & 2.127 & 855 & 2.982 & 28,67 \\
\hline 2011 & 4.517 & 1.972 & 6.489 & 30,39 \\
\hline 2012 & 2.830 & 1.339 & 4.169 & 32,12 \\
\hline 2013 & 3.214 & 1.498 & 4.712 & 31,79 \\
\hline 2014 & 2.120 & 909 & 3.029 & 30,01 \\
\hline 2015 & 5.640 & 1.859 & 7.499 & 24,79 \\
\hline 2016 & 3.318 & 1.178 & 4.496 & 26,20 \\
\hline 2017 & 3.477 & 1.096 & 4.573 & 23,97 \\
\hline 2018 & 2.534 & 485 & 3.019 & 16,06 \\
\hline
\end{tabular}

Fonte: Elaboração própria, com base em estudo de Lemos (2005), Sileg da CD e site do SF. 
No trabalho de Lemos (2005), durante os dezessete anos pesquisados, ela aponta uma média de $35 \%$ de proposições de controle, portanto rebatendo a assertiva de que o controle é inexistente (O`DONNELL, 1998). Não obstante uma diminuição da média, para cerca de $30 \%$, a atividade de controle permanece ao se incluir mais 14 anos (de 2005 a 2018).

De 2005 a 2008, segundo biênio do primeiro mandato e o primeiro biênio do segundo mandato do presidente Lula, os valores são acima de $30 \%$, os quais diminuem para menos de 30\% ao final de seu segundo mandato. A presidente Dilma inicia 2011 e segue até 2014 com valores próximos a $30 \%$. E, então, resta o exato período da $55^{\text {a }}$ Legislatura, quando os valores são bem abaixo da média, com $23,58 \%$ de atividade de controle. Em toda a série histórica, é a menor média quando se compara as legislaturas. Observa-se, no entanto, que ocorreu um aumento da atividade legislativa, o maior volume de proposições apresentadas do tipo PEC e PLs, e a manutenção dos instrumentos de controle em patamares semelhantes ou até menores causaram essa média reduzida em quase dez pontos percentuais.

A tabela 3 adota a metodologia mais ampla para ambas as variáveis: proposições legislativas e Instrumentos de Fiscalização e Controle. A premissa é considerar um número maior de proposições e, em relação aos control tools, incluir aqueles apresentados nas comissões. Desse modo, percebe-se que a representação não está subestimada como na tabela 2, tampouco superestimada. O relevante é o acréscimo de três pontos percentuais quando se compara com as proposições de plenário, como adotadas na pesquisa de Lemos (2005). Uma média de $8 \%$ contra 5\%, o aumento deve-se ao trabalho das comissões, em especial os requerimentos de audiência com o propósito de fiscalização.

De fato, há o exercício da atividade de controle e fiscalização, todavia, não obstante a repercussão dos acontecimentos da $55^{\mathrm{a}}$ Legislatura, o esforço fiscalizatório fica abaixo da média até então praticada, quando se aplica a mesma metodologia utilizada por Lemos (2005). Por sua vez, ao se adotar a proposta mais ampliada de proposições, constata-se que o Parlamento se dedicou em torno de 10\% das proposições no aspecto de fiscalização. 
Tabela 3 - Apresentação de proposições legislativas versus fiscalização e controle no período de 2015 a 2018 na CD e no SF

\begin{tabular}{lcccc}
\hline Ano & $\begin{array}{c}\text { (a) Proposições } \\
\text { Legislativas } \\
\text { Amplas }^{1}\end{array}$ & $\begin{array}{c}\text { (b) Controle } \\
\text { (RIC, RCA, PFC, }^{\text {PDC }} \text {, REQ }\end{array}$ & $\begin{array}{c}\text { (c) } \text { SIT) } \\
\text { Total }\end{array}$ & $\begin{array}{c}\text { (d) \% do } \\
\text { Total }\end{array}$ \\
\hline $\mathbf{2 0 1 5}$ & 29.372 & 2.890 & 32.888 & 8,96 \\
\hline $\mathbf{2 0 1 6}$ & 18.282 & 1.797 & 20.451 & 8,95 \\
\hline $\mathbf{2 0 1 7}$ & 23.538 & 1.975 & 25.961 & 7,74 \\
\hline $\mathbf{2 0 1 8}$ & 13.427 & 859 & 14.597 & 6,01 \\
\hline
\end{tabular}

Fonte: Elaboração própria, com base nos Sistemas Sileg da CD e do site do SF

Notas:

${ }^{1}$ Além de PEC, PLC e PL, estão incluídos os projetos de resolução, de decreto legislativo, medidas provisórias, requerimentos de audiência pública, que não foram classificados como de fiscalização e requerimentos do processo legislativo.

${ }^{2}$ PDC com fundamento no inciso V do art. $49 \mathrm{da} \mathrm{CF} / 88$.

${ }^{3}$ Requerimentos de audiências públicas classificados como de fiscalização.

Portanto há uma consolidação importante sobre o volume de controle parlamentar, que pode ser utilizada para várias comparações, a exemplo da que será feita a seguir com o emprego de fiscalização por meio do discurso dos deputados.

\section{Controle parlamentar nos discursos de grande expediente da Câmara dos Deputados}

Como dito, optou-se por acrescentar outros vocábulos além de "fiscalização" ao estudo de Raposo (2015), o que aumenta a quantidade de discursos, só na 55ª Legislatura foram mais de cinco mil durante o Grande Expediente. O respaldo para o uso da palavra está protegido constitucionalmente como imunidade material, nos seguintes termos: “Art. 53. Os Deputados e Senadores são invioláveis, civil e penalmente, por quaisquer de suas opiniões, palavras e votos.” (BRASIL, 2020a). Tal condição é resultado da própria separação dos poderes, promovendo condições para a atuação do deputado como representante do povo.

Assim, a contabilização inclui as expressões "fiscalizar", "fiscalização", “controlar", "controle", "TCU” e "CGU” em discurso no Grande Expediente desde 2001, 
a fim de obter dados sobre a atuação do Legislativo "verbalizando" ações de controle e se isso está alinhado quantitativamente com os instrumentos.

O gráfico 1 apresenta dados coletados, os quais demonstram a redução de discursos contendo expressões relacionadas à atividade de fiscalização. Os dados se referem à proporção das expressões vinculadas à fiscalização no total de discursos de Grande Expediente. O primeiro ano verificado foi de 2001, quando 5,49\% dos pronunciamentos continham as expressões. Percebe-se que a linha pontilhada está na descendente, começou com $5,49 \%$ e encerrou com $0,80 \%$. Dessa forma, é visível a diminuição quando confrontados dois períodos, de 2001 a 2010 e de 2011 a 2018, sendo a média $3,84 \%$ e $2,5 \%$, respectivamente. Portanto a diminuição pode ser atribuída ao uso de plataformas próprias, como redes sociais e internet no exercício do mandato parlamentar.

Gráfico 1 - Porcentagem dos discursos de controle proferidos no Grande Expediente no período de 2001 a 2018 na CD

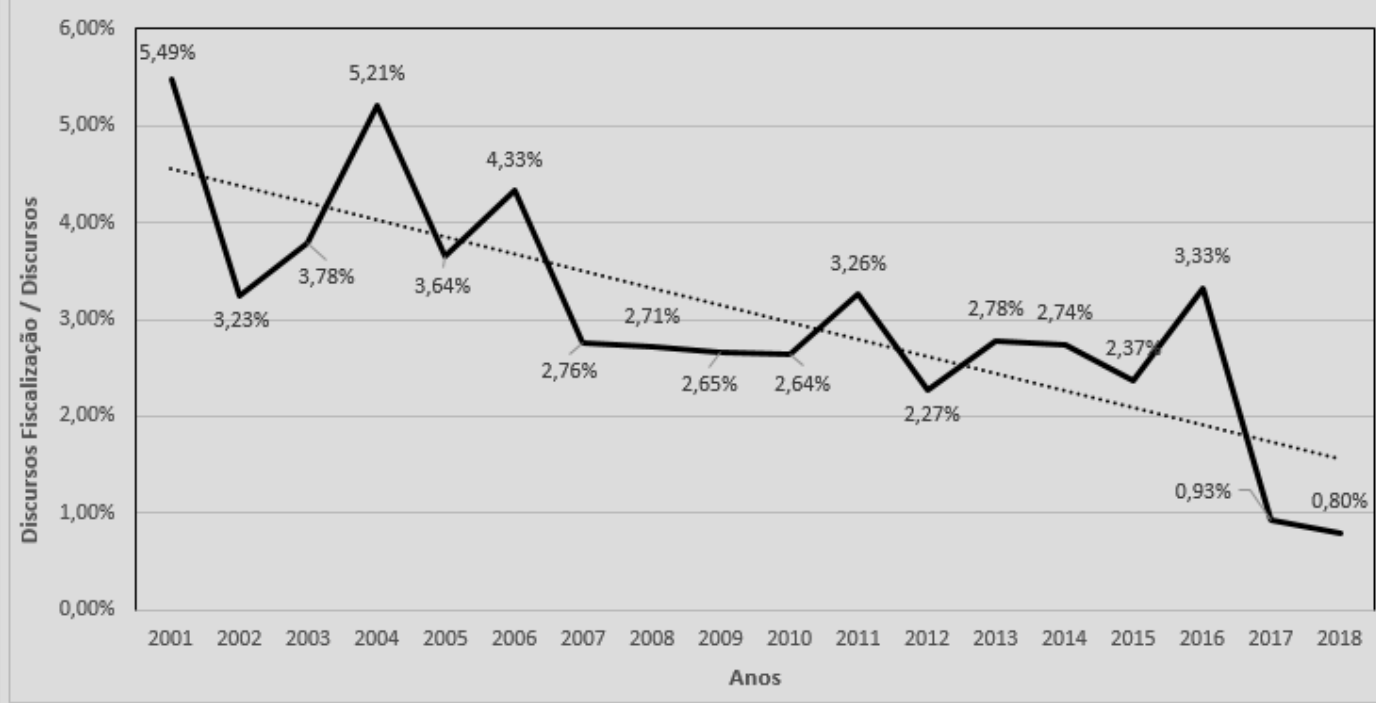

Fonte: Dados oriundos do Banco de Discursos da CD (BRASIL, 2020b).

Nota: A linha tracejada apresenta a tendência de queda da proporção entre os discursos que mencionaram as expressões de controle e o total de discursos proferidos no Grande Expediente pelos deputados.

De fato, se em 2001, 5,49\% dos discursos utilizaram termos conectados ao controle, em 2018 passaram para menos de 1\%, mesmo com a percepção de que o 
“discurso" anticorrupção tenha se intensificado no meio da sociedade nos últimos anos. Em 2016, ano da troca no comando do país, marcado pelo processo de impedimento da então presidente, os temas foram reverberados nos discursos, promovendo uma elevação que alcançou 3,33\%, colocando o ano em sexto lugar em quantidade de discursos e o maior nos últimos dez anos.

Verifica-se ainda ao comparar a tabela 2, contendo o volume de fiscalização, com o gráfico 1, que os anos de 2001 (36,09\% - 5,49\%), 2003 (32,9\% - 3,78\%), 2004 (37,28\% - 5,21\%), $2005(36,83 \%$ - 3,64\%), $2006(30,14 \%$ - 4,33\%) e $2016(26,20 \%-3,33 \%)$ alcançaram o maior peso de discursos contendo viés de fiscalização e controle, sendo que quatro coincidem com maior volume de fiscalização, ou seja, o uso dos instrumentos de controle.

Quanto aos anos de menor porcentagem de discursos: 2009 (26,01\% - 2,65\%), 2010 (28,67\% - 2,64\%), 2012 (32,12\% - 2,27\%), 2015 (24,79\% - 2,37\%), 2017 (23,97\% - 0,93\%) e $2018(16,06 \%$ - 0,8\%), cinco deles também obtiveram a menor porcentagem de instrumentos de fiscalização. Então, ainda não é possível confirmar essa relação direta entre as ações e os discursos, mas percebe-se que há uma conexão, explicada pela necessidade de divulgar seu desempenho durante o mandato, a fim de prestar contas aos seus eleitores.

Em estudo considerando mais de cem mil pronunciamentos feitos no Pequeno Expediente $^{9}$, por mais de dois mil oradores diferentes ao longo de mais de quinze anos de atividade parlamentar na $\mathrm{CD}$, entre outros achados, foi verificado que os deputados apresentam estratégia de concentração temática semelhantes. Há uma opção em difundir a fala por vários temas, são poucos os que concentram em um leque pequeno de assuntos. Sendo a agenda social e econômica preponderantes, não há numericamente representatividade de discursos voltados ao controle no estudo (MOREIRA, 2016).

Voltando a esta pesquisa, o deputado se dirige à tribuna para anunciar as proposições que ele tenha apresentado, o que pode explicar as coincidências encontradas. Além disso, utilizou-se um dos momentos possíveis, o Grande Expediente, porém há

\footnotetext{
${ }^{9}$ Pequeno Expediente: com duração de sessenta minutos improrrogáveis, destinado à matéria do expediente e aos oradores inscritos que tenham comunicação a fazer (Art. 66, I) (BRASIL, 2020b).
} 
outras oportunidades em que ele pode atuar oralmente comentando a proposição e exercendo o papel de fiscal dos atos do Poder Executivo, o exemplo é o ambiente da comissão da qual seja membro e venha a possuir mais chances de usar a palavra em comparação com o plenário. Assim, expõe-se um campo interessante a ser investigado, a atuação de fiscalização e controle por intermédio do uso da palavra, tão significativa no meio parlamentar.

Portanto entende-se como resultado da pesquisa a permanência da atividade de controle no período de 2005 a 2018, uma diminuição de seu emprego no período da $55^{\text {a }}$ Legislatura e há possível correlação entre o volume de controle e os discursos proferidos pelos deputados durante o Grande Expediente.

\section{Conclusão}

O parlamentar escolhido pelos cidadãos tem a missão de fiscalizar os atos e decisões emanados pelo Poder Executivo. Tal função materializa-se por meio dos Instrumentos de Fiscalização e Controle (control tools) e pelo uso da palavra, pois a atividade de discursar é inerente ao exercício do mandato parlamentar (SILVA, 2020).

A pesquisa quantificou o emprego dos IFC pela CD e pelo SF, ou seja, em que medida se apresentaram os seis instrumentos em comparação com as demais proposições legislativas. Lemos (2005) fez levantamento de 1998 até 2004, logo, para continuar essa série histórica, adotou-se, de início, a mesma metodologia para constatar uma média abaixo das anteriores na $55^{\mathrm{a}}$ Legislatura, somando 23,58\%. Assim, se havia em média $30 \%$ de espaço destinado ao controle e fiscalização até então, utilizando o mesmo critério, identificou-se uma queda do esforço fiscalizatório. Todavia, a redução é ainda maior, pois a pesquisa empregou metodologia mais ampla e realista, incluindo as principais proposições legislativas, de acordo com o art. 59 da CF/88 (BRASIL, 2020a), e acrescentou os demais Instrumentos de Controle e Fiscalização, obtendo-se uma média abaixo de $10 \%$.

Quanto ao uso do discurso parlamentar com propósitos de fiscalização, encontra respaldo na própria $\mathrm{CF} / 88$, que protege os deputados por quaisquer de suas opiniões e palavras, e com aplicação dos procedimentos, encontrou-se a possível relação entre o discurso de Grande Expediente e as ações de cunho fiscalizatório, explicada pela própria 
essência da atividade parlamentar de divulgar seu desempenho durante o mandato, a fim de prestar contas aos seus eleitores, na esteira da teoria distributivista, objetivando a reeleição. No decorrer de quase duas décadas, o uso da palavra pelos deputados contendo objetivos de fiscalização decaiu proporcionalmente. Tanto no caso dos instrumentos formais quanto nos discursos percebe-se a diminuição da atividade mesmo em um período marcado por eventos importantes, como a Operação Lava a Jato ${ }^{10}$ e o próprio impeachment da presidente Dilma Rousseff.

Há, sem dúvida, um profícuo campo de pesquisa a ser explorado envolvendo o discurso parlamentar e a atividade congressual, em especial no campo de fiscalização parlamentar. É possível incluir outros momentos das 39 sessões legislativas, as comissões parlamentares e até mesmo a adoção de outros veículos de comunicação.

Em suma, o uso da palavra no decorrer do período de Grande Expediente na Câmara dos Deputados de 2001 a 2018 regrediu proporcionalmente, indicando que ou os deputados migraram para outras formas de exercício e/ou realmente houve uma diminuição da fiscalização por meio da vocalização.

\section{Referências}

BRASIL. Ministério Público Federal. Entenda o caso. Brasília: MPF, 2021. Disponível em: http://www.mpf.mp.br/grandes-casos/lava-jato/entenda-o-caso. Acesso em: 10 jan. 2021.

BRASIL. [Constituição (1988)]. Constituição da República Federativa do Brasil de 1988. Brasília, DF: Presidência da República. 2020a. Disponível: https://bit.ly/2TaVBwA. Acesso em: 10 jan. 2021.

BRASIL. Câmara dos Deputados. Discursos e debates: banco de discursos. Brasília: Câmara dos Deputados, 2020b. Disponível em: https://www2.camara.leg.br/atividade-legislativa/discursos-enotas-taquigraficas. Acesso em: 10 jan. 2021.

BRASIL. Câmara dos Deputados. Regimento Interno da Câmara dos Deputados. 21. ed. Brasília: Câmara dos Deputados, Coordenação de Publicações, 2020c. Disponível em: http://bd.camara.gov.br/bd/handle/bdcamara/18847. Acesso em: 10 jan. 2021.

BRASIL. Câmara dos Deputados. Sistema de Informações Legislativas. Brasília, 2020d. Disponível em: http://bit.ly/2Mr6URn. Acesso em: 10 jan. 2021.

\footnotetext{
${ }^{10}$ A operação iniciou-se em 2009 com a investigação de uma rede de postos de combustíveis e lava a jato de automóveis para movimentar recursos ilícitos pertencentes a uma das organizações criminosas. Depois, seguiram-se dezenas de outras ações envolvendo a Polícia Federal, o Ministério Público Federal e dos estados, o Poder Judiciário e outros órgãos (BRASIL, 2021).
} 
BRASIL. Senado Federal. [Senado Federal]. Brasília: Senado Federal, 2020e. Website. Disponível em: https://www12.senado.leg.br/hpsenado. Acesso em: 10 jan. 2021.

BRASIL. Senado Federal. Regimento Interno do Senado Federal. Brasília: Senado Federal, 2018. Disponível em: https://bit.ly/365jwn. Acesso em: 10 jan. 2021.

CARVALHO, Ginny Carla Morais de. Plenários ao vivo nos parlamentos americano: transparência, publicidade e estímulo à accountability. 2020. Dissertação (Mestrado em Poder Legislativo) - Câmara dos Deputados, Centro de Formação, Treinamento e Aperfeiçoamento (Cefor), Brasília, 2020. Disponível em: https://sucupira.capes.gov.br/sucupira/public/ consultas/coleta/trabalhoConclusao/viewTrabalhoConclusao.jsf?popup=true\&id_trabalho $=97464$ 22. Acesso em: 10 jan. 2021.

CINTRA. Antônio Octávio et al. O poder legislativo na Nova República: a visão da ciência política. In: AVELAR, Lúcia; CINTRA, Antônio Octávio. (Org.). Sistema político brasileiro: uma introdução. 3. ed. São Paulo: Editora Unesp, 2015. p. 81-123.

FOUCAULT, Michel. A ordem do discurso: aula inaugural no Collège de France, pronunciada em 2 de dezembro de 1970. São Paulo: Edições Loyola, 2012.

LEMOS, Leany Barros. Controle legislativo em democracias presidencialistas: Brasil e EUA em perspectiva comparada. 2005. Tese (Doutorado em Ciências Sociais) - Instituto de Ciências Sociais, Universidade de Brasília, Brasília, 2005. Disponível em: https:/www2.senado.leg.br/ bdsf/bitstream/handle/id/180412/tese_leany.pdf?sequence=7. Acesso em: 10 jan. 2021.

MARCIANO, João Luiz Pereira. Fórmula de Yamani. Notas de aula. Instrumentos de pesquisa em Ciências Sociais. 2016. (Disciplina Teoria dos Jogos aplicada à Ciência Política. Curso de Mestrado Profissional em Poder Legislativo. Organizado pelo Centro de Formação, Treinamento e Aperfeiçoamento da Câmara dos Deputados. Brasília-DF. $2^{\circ}$ Semestre de 2016.

MIGUEL, Luis Felipe; FEITOSA, Fernanda. O gênero do discurso parlamentar: mulheres e homens na tribuna da câmara dos deputados. Dados, Rio de Janeiro, v. 52, n. 1, p. 201-221, 2009. Disponível em: https://repositorio.unb.br/bitstream/10482/7127/6/ARTIGOGeneroDiscurso Parlamentar.pdf. Acesso em: 10 jan. 2021.

MOREIRA, Davi Cordeiro. Com a palavra os nobres deputados: frequência e ênfase temática dos discursos dos parlamentares brasileiros. 2016. Dissertação (Mestrado em Ciência Política) Faculdade de Filosofia, Letras e Ciências Humanas, Universidade de São Paulo, São Paulo, 2016. Disponível em: https://www.teses.usp.br/teses/disponiveis/8/8131/tde-04112016-124733/publico/ 2016_DaviCordeiroMoreira_VOrig.pdf. Acesso em: 10 jan. 2021.

MUDALEN, Jorge Tadeu. Discurso sobre o projeto de lei geral das telecomunicações de 2 set. 2015. Brasília, DF: Departamento de Taquigrafia/Câmara dos Deputados, 2 set. 2015. Disponível em: https://bit.ly/3giUgxS. Acesso em: 10 jan. 2021.

O’DONNELL, Guilhermo A. Horizontal accountability in new democracies. Journal of Democracy, Cambridge, v. 9, n. 3, p. 112-126, July 1998. Disponível em: https://muse.jhu.edu/article/16904. Acesso em: 10 jan. 2021. 
RAPOSO, Erivan da Silva. Controle parlamentar e papéis parlamentares: o Legislativo brasileiro a partir da atuação dos deputados federais (1995-2014). 2015. Tese (Doutorado em Ciência Política) — Instituto de Ciência Política, Universidade de Brasília, Brasília, 2015. Disponível em: https://repositorio.unb.br/bitstream/10482/18678/1/2015_ErivandaSilvaRaposo. pdf. Acesso em: 10 jan. 2021.

SILVA, Ronaldo Quintanilha da. Accountability Horizontal: A fiscalização parlamentar exercida pela Câmara dos Deputados na 55 Legislatura. 2020. Dissertação (Mestrado em Poder Legislativo) - Câmara dos Deputados, Centro de Formação, Treinamento e Aperfeiçoamento (Cefor), Brasília, 2020. Disponível em: https:/bd.camara.leg.br/bd/bitstream/handle/bdcamara/40164/accountability _horizontal_silva_pdf?sequence=1\&isAllowed=y. Acesso em: 10 jan. 2021.

Recebido em: 20/02/2021.

Aceito em: 05/04/2021. 